\title{
NANOPARTICLE AS THE STRATEGY FOR THE DEVELOPMENT OF SARS-COV-2 ANTIVIRAL DRUGS
}

\section{SRI HARTATI YULIANI ${ }^{1}$}

1Faculty of Pharmacy, Sanata Dharma University, Paingan, Maguwoharjo, Depok, Sleman, Yogyakarta 55284, Indonesia

Email: srihartatiyuliani@usd.ac.id

Received: 02 Jul 2021, Revised and Accepted: 05 Aug 2021

\begin{abstract}
In just a matter of months, SARS-CoV-2 had spread around the world. Scientists collaborate to solve the problem. The development of antiviral drugs is a challenge in itself due to the rapidly changing nature of the virus. Selection of drug candidates can be done quickly through the repurposing drug method. Broad-spectrum antiviral drugs may be strong candidates for SARS-CoV-2 therapy. Nanotechnology is one solution in the development of antiviral drug delivery systems. The advantages possessed by the nanoparticle system can answer the need for an ideal antiviral drug. This article will focus on the development of nanoparticle preparations as a strategy in handling viruses, including SARS-CoV-2.
\end{abstract}

The selection of article for the current review was searched from specialized databases such as Elsevier, Pubmed, Science Direct, Medscape and other credible databases using the keywords nanoparticle, SARS-CoV-2, Covid-19, drug repurposing, polymeric nanoparticle, micelle, liposome, solid lipid nanoparticle, nanostructured lipid carrier, dendrimer, metallic nanoparticle. The range of articles was 2007-2021.

Keywords: Nanoparticle, SARS-CoV-2, Antiviral drugs

(C) 2021 The Authors. Published by Innovare Academic Sciences Pvt Ltd. This is an open access article under the CC BY license (https://creativecommons.org/licenses/by/4.0/) DOI: https://dx.doi.org/10.22159/ijap.2021v13i5.42604. Journal homepage: https://innovareacademics.in/journals/index.php/ijap

\section{INTRODUCTION}

Severe acute respiratory syndrome coronavirus-2 (SARS-CoV-2) first appeared in Wuhan, China, at the end of December 2019 [1]. Since then, SARS-CoV-2 has spread all over the world ( $>200$ countries) and has become a world health problem [2]. This virus has infected more than 3.1 million people, with a death rate of $>=3.6 \%$ [3]. SARS-CoV-2 is a single-stranded positive RNA virus which is spherical with a diameter of 80-160 nm [4]. SARS-CoV-2 has 4 types of protein in its structure (fig. 1.), namely envelope protein (E), membrane protein $(\mathrm{M})$, spike glycoprotein (S), and nucleocapsid protein (N) [5]. Envelope protein $(\mathrm{E})$ and membrane protein $(\mathrm{M})$ are the constituents that compose the exterior of the SARS-CoV-2 virus, while nucleocapsid protein $(\mathrm{N})$ bonds the viral RNA [6]. Spike glycoprotein $(\mathrm{S})$ facilitated the virus to adhere to the host. Spike glycoprotein (S) facilitates the virus to adhere to the host. Spike glycoprotein $(S)$ will attach to angiotensin-converting enzyme 2 (ACE-2), which allows it to enter the host cell. There are lots of ACE- 2 in the lungs, intestine, and kidneys [6]. The virus mainly targets epithelial cells in the human lungs [7]. Cellular serine protease TMPRSS contained in the host will break the S protein into subunits S1 and S2. Each of the subunits S1 and S2 is responsible for the host cell and membrane fusion bonding process [1, 4]. The virus components and its mechanism to infect humans can be used as the target of drug potential to combat SARS-CoV-2 [1].
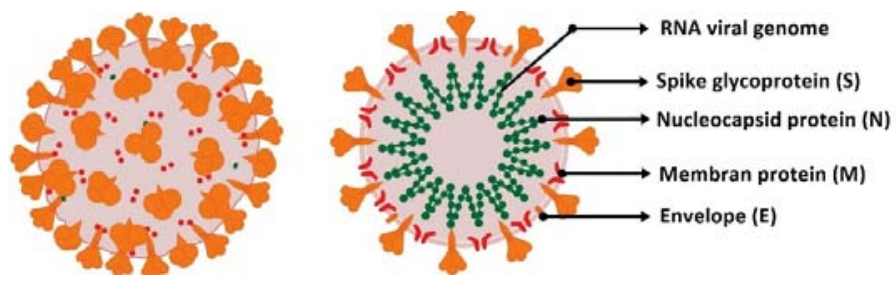

Fig. 1: Image of covid-19 virus and its components [8]

The knowledge about the SARS-CoV-2 infection cycle, its transmission mechanism, and its pathogenesis are important to develop a strategy against the virus. Each stage of the virus infecting the host cell can be used as the target to develop a new therapeutic agent to combat the virus [7]. Several existing researches have pointed some targets (fig. 2) which can be considered to develop SARS-CoV-2 antiviruses, such as spike glycoprotein, ACE-2, TMRSS2 , two viral proteases (3C-like protease/3CLpro and papain-like protease/PLpro), and non-structural protein RNA-dependent RNA polymerase (RdRp) [9]. Several drugs have the potential to be developed as antiviral SARS-CoV-2 (table 1). Some drugs, such as Losartan, Nafamostat, and Comostat, will work by preventing SARSCoV-2 from entering the host cell, while Redemsivir, which classifies as a nucleoside analogue that targets RNA-dependent polymerase (fig. 2), will pressure the viral RNA synthesis [6].

The development of antivirus drugs always has its own challenges. This is caused by the emergence of resistance to the viral strain, which emerges very quickly, and the virus unique trait that allows it to change the host and avoid the antivirus $[10,11]$. Oftentimes there will be adverse effects on the usage of the antivirus drug, such as the usage of Chloroquine, which will induce nausea, diarrhoea, and vomiting, and in some cases, cause fatal toxicity on the cardiovascular at high doses. Lopinavir and Ritonavir may also cause vomiting, nausea, and hepatic injury $[12,13]$.

Furthermore, most antiviral drugs have low solubility and membrane permeability [10], which causes them to not work effectively. Redemsivir is a drug that has poor water solubility. Redemsivir's dissolution becomes the determining factor of its absorption in the lungs. Drugs that will not dissolve will cause adverse effects on the lungs [14]. Losartan is an angiotensin II receptor blocker that has low bioavailability [15]. Ivermectin has poor water solubility and is unstable in water [16]. Darunavir is a protease inhibitor that has poor aqueous solubility. It is a major challenge to develop the oral preparation of darunavir, which has 
good bioavailability [17]. Therefore, innovative drug development is necessary to overcome the weaknesses of viral treatment and drug traits as mentioned earlier. Nano-particle is a suitable drug delivery system candidate for viral treatments, including SARS-CoV-2. Nano- particle advantage at combating antiviral drug problems lies in its ability on increasing bioavailability, protecting the drug, controlling the drug release, decreasing drug resistance, penetrating the cell barrier, and having a specific target $[18,19]$.

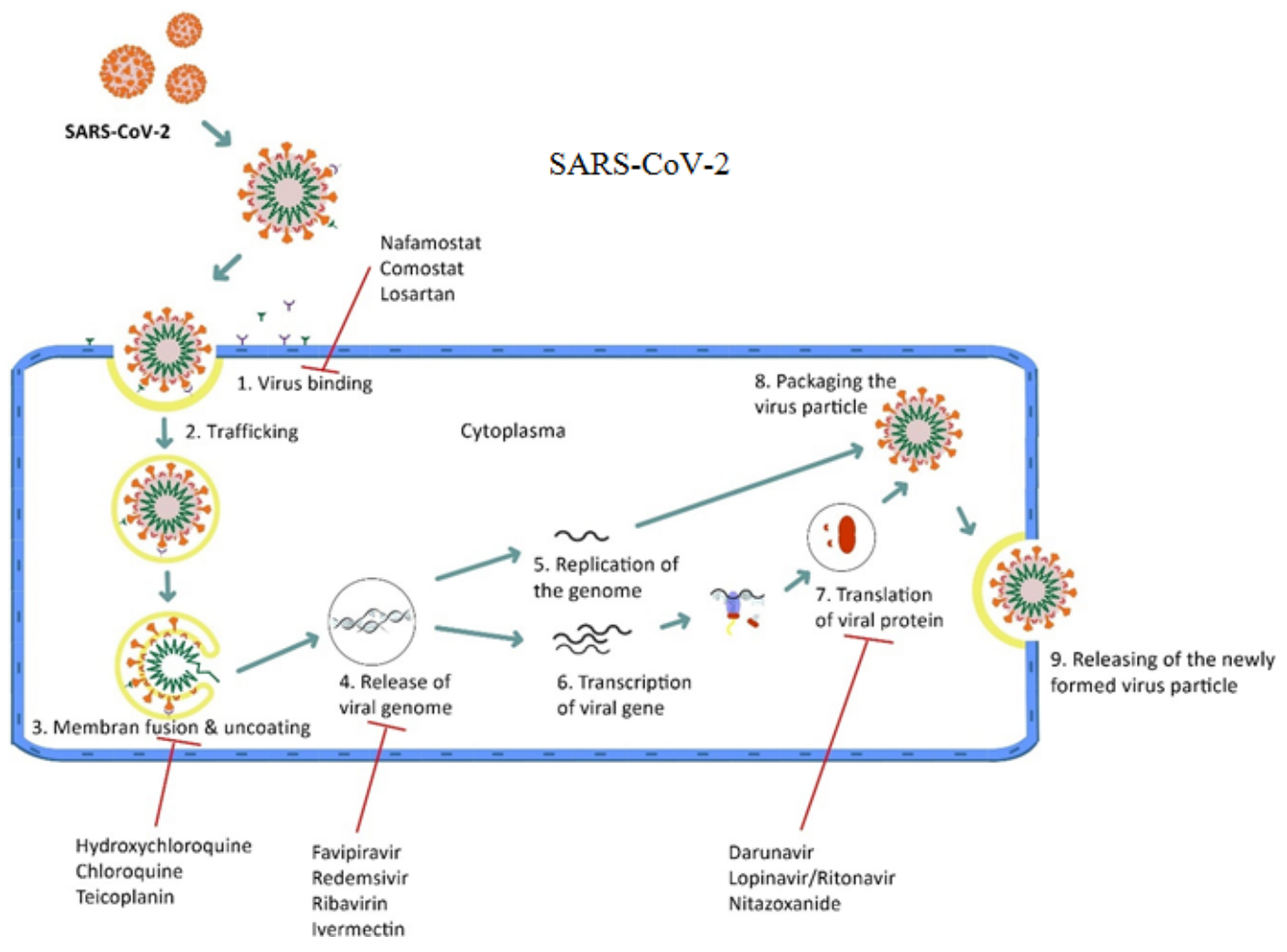

Fig. 2: Picture of the mechanism by which the virus infects human cells and what drugs prevent it [1]

Table 1: List of potential drugs to be developed as SARS-CoV-2 antivirus

\begin{tabular}{|c|c|c|c|}
\hline Agent & Classification & Mechanism of action & Reference \\
\hline Bamlanivimab & immunomodulators & Entrance blocking drug via inhibiting spike protein binding ACE-2 & {$[1]$} \\
\hline Losartan & $\begin{array}{l}\text { Angiotensin II } \\
\text { receptor blocker }\end{array}$ & Entrance blocking drug via blockage ACE-2 & {$[20]$} \\
\hline Nafamostat & antiviral & Entrance blocking drug via inhibiting S-mediated membrance fusion & {$[21,22]$} \\
\hline Camostat & antiviral & Entrance blocking drug via TMPRSS2 inhibitors & {$[22,23]$} \\
\hline $\begin{array}{l}\text { Hydroxychloroquine } \\
\text { and Chloroquine }\end{array}$ & antimalarial & $\begin{array}{l}\text { Endosome fusion blocking agent. It works as a fusion blocking agent by inhibiting } \\
\text { vital lysosome function caused by increasing } \mathrm{pH}\end{array}$ & {$[13,24,25]$} \\
\hline Teicoplanin & antibacterial & $\begin{array}{l}\text { Endosome fusion blocking agent. Teicoplanin blocks cathepsin } \mathrm{L} \text {, which mediated } \\
\text { the cleavage of viral protein so that the virus can't fusion with the host cell. }\end{array}$ & {$[26]$} \\
\hline Favipiravir & antiviral & Favipiravir prevents and inhibits RNA strand elongation and viral proliferation. & [27] \\
\hline Remdemsivir & antiviral & Redemsivir blocks RdRp through its nucleoside component & {$[25,28]$} \\
\hline Ribavirin & antiviral & Ribavirin inhibits replication of the virus by degrading viral RNA & [29] \\
\hline Ivermectin & anthelmintic & $\begin{array}{l}\text { Ivermectin inhibits importin } \alpha / \beta 1 \text {-mediated nuclear import so that it can suppress } \\
\text { the replication of viral RNA. }\end{array}$ & {$[30]$} \\
\hline Oseltamivir & antiviral & Oseltamivir is a neuraminidase inhibitor, which hinders viral expansion to the body. & [31] \\
\hline Darunavir & antiviral & $\begin{array}{l}\text { Darunavir combat SARS-CoV-19 through its main protease enzyme by blocking } \\
\text { SARS-CoV-19 }\end{array}$ & [32] \\
\hline Lopinovir/Ritonavir & antiviral & $\begin{array}{l}\text { Lopinavir and Ritonavir are protease inhibitors. They imitate the normal peptide } \\
\text { linkage and bind to PLpro and 3Clpro. }\end{array}$ & [25] \\
\hline Nitazoxanide & anthelmintic & $\begin{array}{l}\text { It inhibited viral } \mathrm{N} \text { protein expression and pro-inflammatory cytokines and } \\
\text { interleukin } 6\end{array}$ & {$[33]$} \\
\hline
\end{tabular}

\section{Repurposing drug}

SARS-CoV-2 global pandemic needs immediate handling. In SARS$\mathrm{CoV}-2$ therapy, the concept of repurposing drugs has become the norm. Clinical tests with repurposed drugs are being conducted throughout the world to immediately find solutions in regards to the virus [34]. The therapeutic approach by using existing drugs that have been approved for use for other purposes is called drug repurposing [35]. Drug repurposing becomes a promising solution in the development of SARS-CoV-2 drugs because it may reduce time and development costs. The development stages such as chemical optimization, in vitro and in vivo study, toxicity test, production process, formula development, pharmacokinetics profile, and safety test have been surpassed clinically [36, 37]. Drugs that have been used as SARS and MERS antiviral, either single or a combination, are potential to be studied as the remedy to combat SARS-CoV-2 [37]. 
Moreover, antiviral drugs, antimalaria, antiparasite, and corticosteroids are also potential to be developed and evaluated for repurposing as SARS-CoV-2 antiviral [34].

Drug repurposing scenarios in the development of SARS-CoV-2 drugs can be completed in three ways: same target-new virus; same target-new indication; and new target-new indication. The same target-new virus scenario happens when the drug has a specific target on the viral replication and is active towards another virus, then this drug is potential to be used against Covid-19. For example, redemsivir, a broad-spectrum antiviral, has a promising effectivity on the treatment of MERS and SARS. Same target-new indication scenario can be implemented if the drug has the ability to modulate pharmacological target on the pathogenic proses that is related to the viral infection. For example, imatinib (anticancer) hinder Abelson cellular kinase and is found actively combating Coronavirus. Meanwhile, a new target-new indication scenario happens when drugs with some biological activities can identify a new molecule as a target, especially for antiviral replication. Antimicrobe agents such as itraconazole, nitazoxanide, and teicoplanin are found to have activities to prevent the virus from infecting the cells [37].

The first redemsivir was developed to combat the Ebola virus in 2016. Redemsivir is a broad-spectrum antiviral agent with a mechanism to prevent RNA-dependent RNA-polymerase; therefore, it is very potential to be developed as a Covid-19 antiviral agent. Clinical tests on redemsivir combating SARS-CoV-2 that were done by National Institure of Allergy and Infection Diseases (NIAID) show that the patients heal quicker and recover on the $11^{\text {th }}$ day. The study from Gilead Sciences of Foster City California shows that administering redemsivir for $5 \mathrm{~d}$ and $10 \mathrm{~d}$ produce similar clinical improvements. Although there are differences in the clinical test results, FDA allows the usage of redemsivir for Covid-19 treatment [7].

Ribavirin is proven to be effective as a therapeutic agent on the SARS-CoV pandemic in 2003 and MERS-CoV in 2012. Ribavirin works by obstructing RNA-dependent polymerase. Not many clinical tests have been carried out on this drug. Ribavirin has EC50 that is far higher than redemsivir and chloroquine. Moreover, Ribavirin clinical studies against Covid-19 show an adverse reaction, dependent on the toxicity of the toxin and hematologic [7].

Favipiravir is developed by Toyama Chemical Japan in 2014 and has been proven to be effective in treating influenza, Ebola, and norovirus [7]. Administering Favipiravir on Covid-19 patients shows an improvement in their conditions, which is better than administering Lopinavir-Ritonavir. Favipiravir accelerates viral clearance $(4 \mathrm{~d}$ instead of $11 \mathrm{~d})$ with fewer adverse events $(11 \%$ compared to 55.6\%). In Covid-19 patients that received Favipiravir, cough, fever, and respiratory problems decreased [38]. LopinavirRitonavir is a combination of antiretroviral for HIV-positive patients. However, in clinical tests on Covid-19 patients, this combination does not show improvement in clinical outcomes [39].

\section{Nanoparticle as the delivery vehicle}

Nanoparticle is a system that has particles with a diameter of $<200$ $\mathrm{nm}[40]$, while other source defines it as particles that have a size $<1$ $\mu \mathrm{m}$ [41]. Nanoparticles are designed to target diseased cells that allow direct treatment on the cells, increasing efficacy and reducing toxicity [42]. Because of its high surface area to volume ratio, nanoparticles are able to improve the basic properties of drugs and bioactivities. Nanoparticles can improve solubility, stability, pharmacokinetics, biodistribution and bioavailability in addition to targeted delivery, and controlled drug release. Furthermore, the application of nanoparticles can reduce delivered drug's toxicity [43, 44]. The purpose of nanoparticles usage is to increase the effectiveness of the drugs and minimize toxicity. Targeted drug delivery is the most promising strategy to combat SARS-CoV-2.

Based on their unique properties, nanoparticles are suitable as a drug delivery system to fight SARS-CoV-2. The beneficial properties of nanoparticles are related to their small size. These nano-scaled particles can deliver drugs intracellularly and target down to the subcellular level. Nanoparticles can overcome the body barrier so that parts of the body that are difficult to access by drugs can be overcome with this nanoscale system [45]. As a targeted dosage form, some properties of the nanoparticles must be controlled. The properties include size, surface charge, and geometric shape. In order to obtain the desired properties and avoid side effects, the size, surface charge, and geometric shape must be correct. Other required properties are lack of immunogenicity, biodegradability, ease of manufacture, stability, cost-effectiveness, and the ability to release contents only at the site of action [46]. Nanoparticles properties can be adjusted through their composition (organic, anorganic, hybrid), shapes, and surface properties (functional groups, attachment target moieties, surface charges, etc) [43].

The factors that determine the success of nanoparticles as a drug delivery system are their shape and size. Both will influence how the body recognizes the drug and determines its pharmacokinetic properties, targeting ability, and toxicity. The optimal size of the nanoparticles is $100 \mathrm{~nm}$, while the size $>200 \mathrm{~nm}$ will activate the lymphatic system so that the drug will be eliminated quickly. Nanoparticle sizes of around $100 \mathrm{~nm}$ have been shown to significantly increase the amount of drug delivered. The increase in the amount of this drug is related to the high surface area to volume ratio and avoiding elimination by the lymphatic system [46].

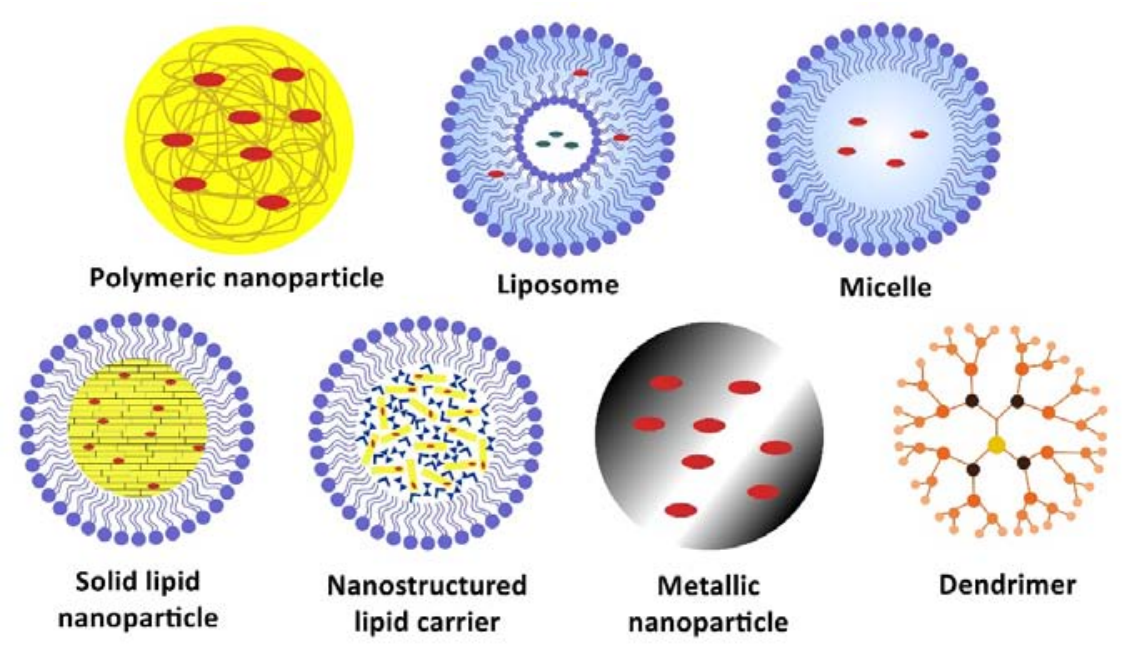

Surfactant Layer Solid Lipid - Hydrophilic Drug - Hydrophobic Drug

$\boldsymbol{\Gamma}$ Liquid Lipid

Fig. 3: Nanoparticle drug delivery system for antiviral [18] 
Nanoparticles have also been developed in viral treatment. Nanoparticles enter the body intranasally and will reach the damaged tissue. Drugs can be actively or passively transferred from the extracellular fluid into the intracellular fluid at the epithelial junction. Then drug targeting will depend on surface properties [18, 47]. One of the applications of nanoparticles is the antiviral acyclovir. Acyclovir is widely used to treat various virus-like varicella-zoster, herpes, and Epstein-Bar virus. Micelle polymers have been used to encapsulate acyclovir so that its solubility and bioavailability are increased [18]. HIV mainly attacks lymphoid tissues. Antiretroviral drugs must be able to penetrate the mucosal epithelial barrier to reach the target organ. Nanoparticles have been applied to the antiretroviral ritonavir, lopinavir, and efavirenz to achieve this goal [47]. Nanoparticles systems used as an antiviral includes liposome, micelle, polymeric nanoparticle (nanocapsule and nanosphere), solid lipid nanoparticle, nanostructured lipid carrier, dendrimer, etc [11].

\section{Liposome}

The word liposome originated from two Greek words that is lipos, meaning fat, and soma, meaning body. Liposomes are first introduced by Dr Alex D. Bangham in 1964 [48]. Liposomes are small spherical carriers made of cholesterol or non-toxic natural phospholipids. Liposomes have a size between 15-1000 nm [18]. The liposome contains one or more phospholipid bilayer membranes, with its polar head will lead to the interior and exterior of the water phase. Because the liposome contains hydrophilic and hydrophobic groups, in the water medium, it forms a spherical double layer. This layer is called the lamella [49].

Liposome shows several advantages over conventional systems, including increasing drug delivery, increasing efficacy, increasing drug stability through encapsulation, reducing systemic toxicity, improving drug performance features, protecting drugs from the environment, biocompatible, and biodegradable. Drug-loaded liposome determines the distribution of the drug in plasma so that it can improve its biodistribution and pharmacokinetics [43]. The aqueous core will trap the drugs during delivery until its release, stimulated by active or passive targeting [18]. One of the reasons liposomes can improve antiviral drug delivery is due to its bilayer structure. It allows liposomes to protect the degradation of the drug in the gastrointestinal tract and other metabolisms, which increase efficacy and bioavailability [48]. Several polymers are used to increase stability, which includes Poly(lactic-co-glycolic acid) (PLGA) and Polyethylene glycol (PEG). The usage of PEG can increase stability in blood circulation. Its biocompatible and biodegradable properties make it perfect as therapeutic carrier [43].

Liposomes have unique properties and can deliver both watersoluble and lipid-soluble drugs [49]. Water-soluble drugs are introduced into the liposome in the aqueous core section and lipidsoluble drugs can be embedded in a lipid. The efficiency of the drug in the liposome is determined by the hydrophobicity of the charge on the liposome surface, the size of the liposome and the fluidity of the dispersion. The characteristics of this liposome will affect its stability and biodiversity. There are several disadvantages of liposomes as antiviral carriers, including low stability both in vitro and in vivo, a low combination of drugs in the aqueous core and lipid bilayer, and expensive production costs [50].

Ivermectin is usually called 22,23-dihydro-avermectin B1 [51]. This drug works by obstructing the replication of viral RNA. The use of Ivermectin can reduce viral RNA by 5000 times in $48 \mathrm{~h}$ [30]. Ivermectin pharmacokinetics behaviour depends on the route of administration, formula used and pathophysiology of the host. The development of drug delivery must be done to achieve optimal Ivermectin bioavailability. One promising dosage form is a liposome. Croci et al. [51] make Ivermectin liposomes by using phosphatidylcholine ingredients originating from soybeans. The study proves that Ivermectin liposomes have lower toxicity than free Ivermectin. Ivermectin's activity as an antiviral is also proven to increase after being formulated as a liposome. The use of Ivermectin liposome proves to reduce more EC50 than Ivermectin alone. Croci et al. also discover that the difference in the formula can cause differences in Ivermectin's effectivity as an antiviral [51].
Lactoferrin of a multifunctional glycoprotein is currently being developed in the treatment of SARS-CoV-2. Lactoferrin liposome shows promising results by inhibiting the entry of viruses, reducing inflammation [52] and having the activities as an immunomodulator. Lactoferrin liposomes will be related to ACE-2 so that SARS-CoV-2 will not interact with ACE-2, which causes it to not be able to enter the host cell. Serrano et al. state that the use of Lactoferrin liposome will significantly improve the condition of SARS-CoV-2 patients in 5 $\mathrm{d}$ [53]. Tai et al. [54] in their research about liposomal hydroxychloroquine found that giving liposomal hydroxychloroquine by inhalation will increase the amount of hydroxychloroquine in the lungs (30 times), the half-life in the lungs is longer (2.5 times), but the blood level is lower than the intravenous administration of free hydroxychloroquine [54].

Liposome is very potential to be developed as one of the drug delivery systems for antiviral drugs, including SARS-CoV-2 antiviral. Either water-soluble or lipid-soluble drugs can be carried by liposomes. Liposome formulations will increase the effectiveness of antiviral drugs and reduce their toxicity as has been proven in Ivermectin, lactoferrin and hydroxychloroquine above.

\section{Micelles}

Micelle is the spontaneous formation of colloidal particles with a diameter of 5-100 nm which has a hydrophobic centre and a hydrophilic surface. Amphiphilic copolymers which have hydrophobic and hydrophilic parts are widely used in the formation of micelles [55]. Micelles form spontaneously at a certain concentration and temperature. At low concentrations, the amphiphilic molecule separates, but as the concentration increases, the amphiphilic molecule will form an aggregation. The concentration of the amphiphilic molecule at which micelles are formed is called the critical micelle concentration. Meanwhile, the temperature at which micelles begin to form is called the critical temperature [56]. The aggregation of surfactants in a liquid colloid medium at a certain surfactant concentration (more than the critical micelle concentration) and a certain system temperature will result in the formation of micelles. Lipid micelles have a single layer of lipid layers with fatty acids and aqua core for each type of oil in water $(\mathrm{O} / \mathrm{W})$ and water in oil $(\mathrm{W} / 0)[8]$.

Polymeric micelles are widely used to increase drug solubility in water, improve bioavailability, reduce toxicity and adverse effects, improve permeability across physiological barriers and increase drug biodistribution $[55,56]$. Micelles can be designed as a targeting drug delivery because 1) they increase the permeability and retention effects; 2) they are made from copolymers which are responsive to stimuli; 3 ) they attach a specific target ligand molecule to the micelle surface [55]. Based on the physicochemical properties of the antiviral or immunomodulatory agent, either the surfactant layer or the core can be used to load the agent [8].

Acyclovir is an antiviral that is widely used to treat various kinds of virus for example, herpes simplex virus (HSV) type 1 and 2, varicella-zoster virus and, to a lesser extent,, cytomegalovirus and Epstein-Barr virus [57]. Recently, Baker [58] states that acyclovir provides a promising solution to treat SARS-CoV-2 patients. Thirty-eight patients with SARS-CoV-2 were given acyclovir treatment. Acyclovir was proven effective, safe and inexpensive for 29 patients, while 9 patients were still being treated. There has been no adverse effect and death so far in treatment (58). Polymeric micelles have been used as a delivery system for acyclovir antiviral. Sawdon et al. [57] made acyclovir micelles using polycaprolactone with methoxy-polyethylene glycol or chitosan. Polycaprolactone was chosen as a vehicle because it is biocompatible and biodegradable. Acyclovir can cause the ringopening of polycaprolactone and ultimately result in the encapsulation of acyclovir by polycaprolactone. Methoxypolyethylene glycol or chitosan is added to improve the physical properties of these preparations. Acyclovir is rapidly released in the first $2 \mathrm{~h}$ followed by a sustained release pattern for up to $48 \mathrm{~h}$. Hydrolysis of the ester bonds between acyclovir and polycaprolactone causes Acyclovir to be released. The polymeric micelle acyclovir exhibits biocompatibility and is non-toxic [57]. 
Ribavirin, an antiviral that works by inhibiting viral RNA replication [28], has been formulated in the form of micelles for hepatocytic targeting by Craparo et al. in 2013. Galactosylated micelles are produced by reacting polyhydroxyethyl-2-aminoethylcarbamat-DL aspartamide (PHEA-EDA), polylactic acid (PLA) and lactose to produce copolymer PHEA-EDA-PLA-GAL. This copolymer is then mixed with Ribavirin to produce galactosylated micelles loaded with Ribavirin using dispersion and ultrasound techniques. The resulting ribavirin micelle galactosylade is $10 \mathrm{~nm}$ in size, spherical in shape and drugloaded with $2.7 \%$. This preparation is stable on plasma mimicking media and extracellular fluid but hydrolyzed by enzymatic activity [59]. By using a suitable polymer, ribavirin micelles can also be developed for SARS-CoV-2 therapeutic purposes.

\section{Polymeric nanoparticle}

Polymeric nanoparticles are solid polymer particles made from natural or synthetic polymers with sizes between 10-1000 nm. Antiviral drugs will be encapsulated into the polymer matrix or absorbed on the surface $[60,61]$. The polymeric nanoparticles in which the drug is encapsulated in it are called nanocapsules $(<300$ $\mathrm{nm}$ ), whereas if the drug is adsorbed on the surface or embedded on the matrix, it is called the nanosphere $(10-200 \mathrm{~nm})$ [62]. These polymeric nanoparticles will increase the solubility of hydrophobic drugs, provide stability in the extracellular environment, and reduce toxicity and have a high therapeutic ratio [43]. They can reach specific target sites in the body because they are nano in size. This system can also be used as controlled drug delivery [61]. For certain purposes, the hydrophobic polymeric surface of the nanoparticles can be modified. The modification of the surface can be carried out by physical adsorption of the protective polymer on the particle surface or by chemical grafting of the polymer chain onto the particles. An example of the modification of surface using the absorption of polyethylene oxide and polypropylene oxide copolymers on the surface of polystyrene latex particles through hydrophobic interactions. The surface of polystyrene nanoparticles can also be altered with dextran and dextran-PEG copolymers by means of a hydrophobic bonding mechanism. Other copolymers that are widely used in surface modification are PEG copolymers and polylactide-glycolide (PEG-PLAGA) [63].

The polymeric surface properties of the nanoparticles can be adjusted to allow for incorporation with various drugs as well as antigens. The modification of the surface with hydrophilic polymers such as PEG is essential to minimize nonspecific interactions with serum proteins and to avoid phagocytic uptake, thereby extending half-life and improving pharmacokinetic profiles. The delivery of vaccines using polymeric nanoparticles has been known to induce anti-inflammatory and immune responses to $\mathrm{T}$ cells. Usually, this type is made by mixing the polylactic-co-glycolic acid polymer with influenza epitope at solvent [9].

Ribavirin has been widely used as an antiviral agent by inhibiting RNA replication. In conventional therapy against viral infections (hepatitis C) Ribavirin will cause dose-dependent hemolytic anemia [64]. In their research, Wu et al. [65] state that the level of Ribavirin in red blood cells (RBC) is 5 times the level in peripheral blood mononuclear cells (PBMNC). PBMNC describes the amount of Ribavirin in the liver. This is what causes hemolytic anemia [65]. Abo-zeid and Garnett in their research, found that polymeric Ribavirin nanoparticles were found in low amounts in RBC so that polymeric Ribavirin nanoparticles could be used to improve the therapy of viral infections in the liver by increasing efficacy and minimizing side effects [64].

\section{Solid lipid nanoparticles}

Solid lipid nanoparticles (SLN) are a system similar to liposomes but differ in their lipid aggregation status [17]. Solid lipid nanoparticles have spherical shapes with a diameter of 50-1000 nm. The essential ingredients for the manufacture of SLN are lipids that are in a solidstate at room temperature, emulsifiers, active pharmaceutical ingredients (API) and a suitable solvent system. The advantages of
SLN over liposomes are 1) avoiding the use of organic solvents; 2) has good reproducibility and allows it to be produced on a large scale; 3) enhances stability due to its rigid lipid matrix; 4) has a large entrapment efficiency against hydrophobic drugs; 5) has the ability for controlled release. This SLN changes the dimensions of drug delivery by combining the advantages of microemulsions, liposomes and polymeric nanoparticles. This SLN can also be used intravenously because an aqueous solution or aqueous surfactant can be dispersed spontaneously [66]. The small particle size is also the key to delivering the drug to the target. The size of solid lipid nanoparticles $<10 \mathrm{~nm}$ will be able to diffuse into the blood capillaries, the size of $10-100 \mathrm{~nm}$ can deliver drugs into the lymphatic capillaries by convection, while the dimensions of 100 $200 \mathrm{~nm}$ its ability to diffuse rapidly has decreased [67].

The critical elements that determine the efficiency of delivery include particle size, surface charge, PEGylation, and surface modification by the target ligand [67]. Solid lipid nanoparticles can undergo phagocytic uptake, which can be minimized by surface modification. Cyclodextrins are widely used to increase solubility in water, increase bioavailability and improve physicochemical properties of drugs with their inclusion complexes. The addition of a cyclodextrin inclusion complex to the SLNs will improve the drug release profile of the system. Liquid SLN stability is also good. Aqueous SLN is stable for 3 y of storage. The tendency of SLN to gel formation related to long storage and light exposure can be overcome by lipid modification [66].

The SLN consists of a phospholipid lining a solid hydrophobic central matrix (containing the hydrophobic tail of the phospholipid). The SLN also contains solid lipids, emulsifiers and also active pharmaceutical ingredients (APIs). APIs that are incorporated into SLN include drugs, proteins, plasmids, DNA, and genes. The lipids used in the SLN formation are surfactants which are thus stabilized at physiological temperature and are solid in room form. Based on its structure, the lipid is divided into fatty alcohols, fatty acids, fatty esters, triglycerides and partial triglycerides. Emulgators that are widely used in SLN are nonionic polymers, ionic polymers, surfactants and organic salts [66].

The formation of colloid nanoparticles is related to the interface and surface tension between the two fluids. The main principle of SLN formation is the adhesion force of two liquids. Usually, the interface tension of two liquids is bigger than its surface tension because the attractive forces are weaker than that of gases. The molecules at the interface get free energy from the interface stress when they are agitated and form a spherical system to minimize free energy. Solid lipid nanoparticles are very similar to the emulsion, where solid lipids, which is melted and mixed with the aqueous phase, are used as substitutes for the oil phase. High-speed agitation used in this mixture will result in the formation of one dispersed phase droplet in the dispersion medium. When a surfactant is added as the third substance, the interface tension between the two liquids decreases, thereby reducing the surface energy and forming a stable SLN [66]. The SLN preparation method can be done by high-pressure homogenization, solvent evaporation, ultrasonication, solvent emulsification-diffusion/solvent emulsification evaporation, microemulsion based, supercritical fluid, double emulsion, spray drying, precipitation, ultrasound dispersion film, solvent injection, coaservation, and membranes contractor methods [68].

FDA has approved the Lapinovir of a protease inhibitor [24] for use as an antiviral for SARS-CoV-2 [69]. Ravi et al. in 2014 have formulated lopinavir into SLN preparations. SLN loaded lopinavir is made with stearic acid as a solid lipid. The resulting SLN has a particle size of 233 $\mathrm{nm}$ with an efficiency of entrapment of $83 \%$. Compared to commercially available preparations, SLN loaded with lopinavir has 5 times the bioavailability [70]. In 2017, Javan et al. encapsulated ritonavir in SLN. They concluded that the SLN could efficiently encapsulate ritonavir, maintain its antiviral activity, and modulate drug release as a promising nanocarrier carrier. SLN provides a good capacity for hydrophobic antivirals such as ritonavir [71]. 


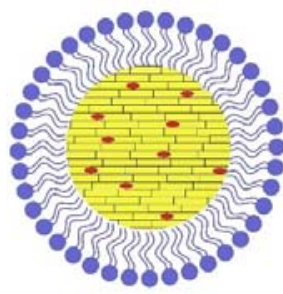

SLN

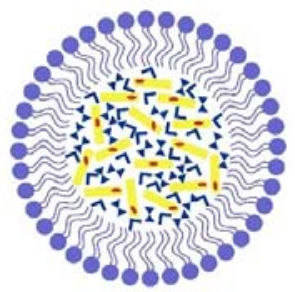

imperfect crystal NLC

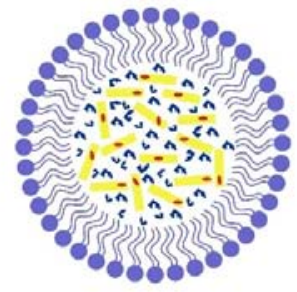

amorphous NLC

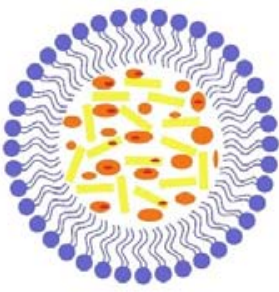

multiple type NLC

$\Gamma \quad$ Liquid Lipid

Liquid Lipid

Oil Liquid

A Amorphous LL
Solid Lipid
Hydrophobic Drug
Surfactant Layer

- Hydrophilic Drug

Fig. 4: Solid lipid nanoparticle and nanostructured lipid carrier [76]

\section{Nanostructured lipid carrier}

Nanostructured lipid carrier (NLC) is a drug delivery system consisting of a combination of solid and liquid lipids as its core matrix, with sizes between 10-1000 nm [72, 73]. The basic ingredients for making NLC are biodegradable and biocompatible (solid and liquid) lipids and emulsifiers [73]. This NLC is a development of SLN in order to overcome the weaknesses of SLN [74]. SLN has advantages because it uses physiological lipids, it does not use organic solvents, and it can be applied on the production scale. As an SLN delivery system, it can increase bioavailability, protect the drug from the environment, and have a controlled release character. However, SLN also has disadvantages, including unpredictable gelation tendency, polymorphy transition, low incorporation caused by the solid lipid crystal structure, drug release from the matrix during storage $[72,75]$. The NLC formulation is based on incorporating the drug in a mixture of various ratios of solid and liquid lipids. NLC is designed to produce less/no crystalline matrix in the compacted core to overcome the weakness of SLN. The preparation method between SLN and NLC is not different, the difference between the two is in the composition of the core/matrix [75]. Core NLC is made from a mixture of solid and liquid lipids, which form an imperfect crystalline interior that aims to improve the capacity of the drug. The liquid phase in NLC inhibits drug release during storage [67]. The addition of liquid lipids to the NLC matrix is a fundamental step, as it significantly increases its properties compared to SLN [76].

These nanocarriers can be used to transport both hydrophilic and lipophilic drugs. This NLC can be used by oral, parenteral, ocular, pulmonary, topical or transdermal routes. Based on the location of the combined drugs, NLC is divided into 3 types, namely imperfect crystal model, amorphous model, multiple types (O/F/W) (fig. 4) [73]. Imperfect crystal LNC consists of an irregular matrix with many cavities which accommodate more drugs in the amorphous cluster. This imperfection occurs by mixing an appropriate amount of solid lipid with liquid lipid. The addition of fatty acids of various chain lengths and mixtures of mono-, di-, and tri-glycerols to the matrix make it irregular. This imperfect crystal core formation allows more drugs to be added and avoids the regularity of the matrix, which will cause the drug to be pushed out. Amorphous LNC is made by carefully mixing solid lipids and liquid lipids to minimize drug leakage during the crystallization process. The lipids used such as hydroxyoctacosanyl, hydroxystearate, isopropylmyristate or dibutyl adipate form a non-crystalline matrix. The core matrix is in a homogeneous amorphous condition. The advantage of this type of drug remains in the core of the matrix $[73,75]$. Multiple LNCs are oilin-fat-in-water $(0 / F / W)$ carriers consisting of a solid lipid matrix that encloses multiple water oil nano compartments. It is suitable for highly oil-soluble drugs; this system will increase the capacity and stability of the drug. Small oil droplets are evenly dispersed into the solid lipid matrix then this system is dispersed into the aqueous medium. This type provides the advantage of high absorption efficiency, controlled drug release, and minimizes leakage $[73,75,76]$.

The constituent ingredients of NLC include solid lipids, liquid lipids, emulsifiers, both hydrophilic, lipophilic and amphiphilic emulsifiers as shown in table 2. Lipids are the main components of NLC to build drug storage capacity, long action, and stability. This solid lipid will be in a solid state at room temperature and will melt at high temperatures $\left(>80^{\circ} \mathrm{C}\right)$ during the manufacturing process. Liquid lipids commonly used in NLC are digestible oils from natural sources. Fatty acids such as linoleic acid, decanoic acid, and oleic acid can also be used. The tocols group such as $\alpha$-tocopherol can be used as a liquid lipid in NLC because of its stability, easy large-scale production, and good solubility by lipophilic drugs. The use of natural oils has also gained popularity insofar as it demonstrates physical acceptance and chemical stability. Examples of natural oils that have been used are Siberian pine seed oil and fish oil [72].

The lipids used in NLC should be physiologically acceptable, biodegradable, non-toxic, and generally known to be non-toxic. Lipid type and structure will influence the character of NLC. The solubility and the partition coefficient of the drug in the lipids are the main considerations for the selection of a suitable lipid. The solubility of drugs in lipids will reflect drug loading and encapsulation efficiency. The degree of lipid crystallization will affect drug uptake, size and load, and efficacy. The higher the viscosity of the dispersion phase due to the higher the melting point of the lipids, the higher the average particle size [73].

Table 2: NLC constituent additives

\begin{tabular}{lll}
\hline Ingredient & Material & Reference \\
\hline Solid lipid & $\begin{array}{l}\text { Glyceryl behenate, glyceryl palmitostearate, lipid acid (stearic acid), monoglyceride, diglyceride, } \\
\text { triglyceride, steroid (for example, cholesterol), wax (for example, cetyl palmitate) }\end{array}$ \\
Liquid lipid & $\begin{array}{l}\text { Medium-chain triglycerides, squalene, paraffin oil, isopropyl myristate, propylene glycol dicaprylocaprate, } \\
\text { 2-octyl dodecanol }\end{array}$ \\
Emulsifier/surfactant & $\begin{array}{l}\text { Poloxamer 188, polysorbates (tween), polyvinyl alcohol, sodium deoxycholate, span, Lecithin, } \\
\text { phosphatidylcholine, phosphatidilethanolamines }\end{array}$ \\
\hline
\end{tabular}

Surfactants will affect the quality and efficacy of NLC. The physical stability, toxicity, and crystallinity of NLC are affected by the type and concentration of surfactants. The surfactant selection was based on the administration route, hydrophilic-lipophilic balance, effect on particle size and the modification of lipid. Emulgators are adsorbed on the surface of the interface to reduce the surface tension. In the process of NLC formation, crystallization occurs with compaction and the surface area of the particles increases rapidly so that the entire system 
becomes unstable because the surface tension increases rapidly. Therefore, surfactants are needed to reduce the interface stress in order to achieve a stable system. Modifying the composition of the surfactant system can result in a mismatch of the chemical components of the NLC, which results in system stability [73].

Lopinavir, an HIV antiretroviral, has been approved by the FDA as a cure for SARS-CoV-2 infection [69]. Khan et al. [77] studied the manufacture of NLC loaded lopinavir using the high-shear homogenization method. The resulting NLC was then dried in a freeze dryer using trehalose as a cryoprotectant. The resulting NLC loaded with lopinavir had a particle size of $\pm 286.8 \mathrm{~nm}$ and an absorption efficiency of \pm 88 .31. The increase in particle size after the 6-month stability study was only $\pm 40 \mathrm{~nm}$. The bioavailability test of lopinavir NLC in male Wistar rats showed an increase of 6.98 times compared to the lopinavir suspension [77]. Meanwhile, Garg et al. [78] also conducted the NLC formulation of lopinavir with a hot-melt micro emulsification method using compritol 888 and oleic acid as a solid and liquid lipid. This study found that the AUC NLC profile increased 16.5 times while the biodistribution of lopinavir in the brain increased 2.8 times compared to plain lopinavir [78].

\section{Dendrimer}

Dendrimer is a globular macromolecule with an architecture consisting of three distinct domains: the central core, the branched mantle, and the corona with peripheral reactive functional groups. Dendrimer has a size of 1-100 $\mathrm{nm}$ [79]. The name dendrimer was introduced by Tomalia from two Latin words that is dendros, which means tree, and meros, which means part [80]. So that dendrimer can also be defined as a polymer group with high regularity, 3-dimensional shape, and is a functional polymer like a tree. In contrast to classical random coil polymers, dendrimers have a special architecture consisting of a central core, hyper-branch mantle/interior layer, corona with reactive group functional groups in the outermost branch unit $[79,81]$. The central core consists of 1 atom or a group of atoms that have at least 2 chemical functionalities that can be bonded as branches. Interior layers are unit repetitions that have at least one branch where the repetitions are arranged in a geometrical progression to produce a series of concentric radial layers called generations (fig. 5). Corona is the outermost layer of macromolecules that determines the efficacy of nucleic acid complexes or trapped drugs [82].

Dendrimer is made in 2 ways, namely convergent and divergent. In the divergent method, the formation process starts from the central core, followed by the construction of one monomer layer or generation at a time. The central molecule interacts with a monomer molecule containing one reactive group and two (or more) inactive groups. On the other hand, in the convergent method, the dendrimer formation starts from the end group and ends at the centre. In this convergent approach, the outer branch surface subunit is reacted with a single fused unit having two (or more) associated active sites and a distal inactive site [82].

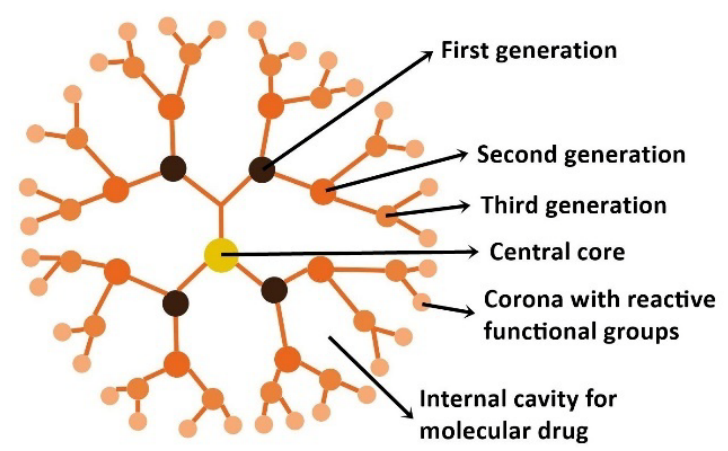

Fig. 5: The structure of dendrimer [10]

The dendrimer-making strategy causes the result to be monodisperse. The size of the dendrimer is determined by the number of generations; the more the number of generations, the bigger the size of the dendrimer. Polyamidoamide is one of the most widely used dendrimers where generation $1-10$ goes up from 1.1 to $12.4 \mathrm{~nm}$. The size of these dendrimer particles will affect their circulation time in the blood. Dendrimer has a multifunctional surface that allows it to modify solubility and its interactions with other molecules in a variety of environments. Modifications to the dendrimer surface will provide a great opportunity to increase drug solubility, increase biocompatibility and permeability in the cellular environment [83]. Many compounds that are strong candidates for a drug stop development because of their solubility in water. Dendrimer is a strong candidate to tackle this problem. The increase in water solubility is achieved in two ways, namely entrapment/encapsulation of the drug into the dendritic structure or drug interactions with the peripheral part of the dendrimer [84]. The complex formation in dendrimers occurs due to dispersion forces, hydrogen bonding, electrostatic interactions, or hydrophobic interactions. These interactions will determine the stability of the drug-dendrimer complex and the mechanism of drug uptake into cells [83].

The internal dendimer structure is hydrophobic due to hydrophobic interactions and hydrogen bonds in its formation; therefore, it is very suitable to encapsulate/absorb hydrophobic drugs. The higher the dendrimer generation, the more room to encapsulate the hydrophobic compounds. However, with the increasing number of dendrimer interior surface generation will decrease significantly due to "de genes dense packing" and structural folding. Apart from the advantages of dendrimer in increasing solubility, there are also disadvantages. One of the drawbacks of dendrimers is that if they are exposed to biological fluids, they may fail to control drug release due to their weak drug-dendrimer interaction [84].

In the development of antimicrobial drugs, various classes of dendrimers can be used as antimicrobial agents, drug delivery systems, and bacteriophobic coatings. The antimicrobial activity of dendrimer is closely related to the multivalency of the surface, which is determined by the tree-like structure and the abundance of active groups. The antibacterial activity of dendrimer depends on the interaction of positive dendrimer charge and negative charge on the bacterial membrane surface, its ability to penetrate the bacterial membrane, and the destruction of the lipid bilayer. Cationic dendrimers have high antimicrobial activity due to their positive charge [85].

Dendrimer also shows the activity as an antiviral. Dendrimer works as an antiviral by preventing viral binding to target cells or preventing viral genome replication. Dendrimer functionalized with sialic acid with a size similar to that of the influenza virus succeeded in inhibiting the host-virus interaction. This sialic acidfunctionalized dendrimer has better hemagglutination inhibition power than the monomeric sialic acid. Dendrimer polyamidoamine (PAMAM) functionalized with sialic acid is very effective against murine influenza pneumonitis infection. Dendrimeric polyanionic can inhibit HIV, HSV, and other viruses by targeting the viral life cycle and preventing viral binding to host cells [85]. Anionic dendrimer PAMAM and cationic dendrimer have been shown to increase antiviral activity The Middle East respiratory syndrome coronavirus (MERS-CoV) [86]. Polyamidoamine conjugated generation 4 sialic acid has also been shown to prevent H3N2 influenza pneumonitis virus infection [87]. Polyanionic carbosilane in vitro and in vivo showed activity against Herpes Simplex Virus (HSV) and human immunodeficiency virus (HIV) [85]. The positive charge of carbosilane dendrimers will interact with the negative charge of nucleic acids to form dendriplexes. This structure protects the nucleic acid content from degradation, thereby increasing its levels reaching the target cells. This method can be applied to RNAbased viruses such as SAR-CoV-2 [17].

\section{Inorganic nanoparticle}

Nanoparticles are divided into 2 major groups, namely organic nanoparticles and inorganic nanoparticles. Inorganic nanoparticles include mesoporous silica nanoparticles, silver nanoparticles (AgNPs), gold nanoparticles (AuNPs), carbon nanotubes and quantum dots. One of the advantages of inorganic nanoparticles over organic nanoparticles is that the modified surface can be adjusted and the size can be determined [88]. Among the inorganic 
nanoparticles or metallic nanoparticles, AgNPs and AuNPs showed high activity against viruses. These two types of metal nanoparticles have shown effectiveness against the influenza virus, HIV-1, HSV, and dengue virus type-1. The interaction of metallic nanoparticles and proteins on the viral surface occurs through the interaction of Kazimir and Van der Waals forces which make them inactive [62]. Metallic nanoparticles for drug delivery are solid colloidal particles with a particle size range of $10-1000 \mathrm{~nm}$ containing the drug dispersed in the polymeric carrier matrix, encapsulated in the polymeric shell, covalently bound or adsorbed on the particle surface or encapsulated on the structure [89]. Metallic nanoparticles have a size of 1-100 nm. Two methods to produce metallic nanoparticles are bottom-up (selfassembly) and top-down. The bottom-up method refers to the levelby-level nanoparticle constructions, while the top-down refers to the use of chemical or physical methods to decrease the particle size to the desired size [90].

Metallic nanoparticles synthesis can be carried out by 3 methods, namely physics, chemistry and biology. UV radiation, microwave irradiation, laser, photochemical, thermolytic, and sonochemical are physical methods of forming metal nanoparticles. This technique can prevent solvent contamination and generate monodisperse nanoparticles and uses a top-down approach. Synthesis occurs from metal atoms evaporation to rapid, controlled condensation where the metal atoms rearrange and gather to form small nanoparticles clusters. Chemical synthesis uses a bottom-up approach with techniques such as chemical vapour synthesis, sol-gel methods, hydrothermal synthesis, polyol synthesis, and microemulsions. The nanoparticles generated from this method can be determined in size, dimensions, composition and structure. Inorganic and organic solvents are often used as reducing sugars in this chemical synthesis. To prevent agglomeration, it is necessary to add a stabilizing agent. The biological synthesis method uses a bottom-up approach. This method requires biological organisms, including bacteria, viruses, algae, yeast, fungus, and plants. The advantages of this method are size and morphology can be determined, biocompatible can be produced on a large scale quickly, and ecofriendly [91].

AuNPs is widely preferred because of its excellent conductivity, flexible surface modification, biocompatibility, and simple manufacturing method. Another advantage is that AuNPs has unique physical and chemical properties, the gold core that is inert and nontoxic, photophysical properties, and versatility of function through thiol bonds. Photophysical properties can aid in efficient drug release at remote sites [90]. AuNPs is synthesized by chemical reduction of chloroauric acid ( $\mathrm{HAuCl} 4)$ using a reducing agent. AuNP has a size of 1-150 nm [92]. AuNPs is a red wine-colored solution. AuNPs has a variety of shapes, including spherical, multiple twined, hexagonal platelets, octahedral, sub-octahedral, decahedral, multiple twined isosahedral, tetrahedral, nanotriangel, nanoprism, nanorods, and irregular shape. The advantages of AuNPs are that it is nontoxic, has a high surface area and is readily modified with target molecules for biomedical purposes [93]. AuNPs has a negatively charged surface, this facilitates the functionalization of a wide variety of biomolecules such as drugs, genes and target ligands. Drug molecules can directly conjugate with AuNPs via ionic or covalent bonds or physical absorption [94].

AuNPs is able to reach and then enter cells that are used by the HIV as a replication site, such as macrophages, lymphocytes, and microendothelial cells. For this purpose, the thiol group is used as a linker between AuNPs and the drug Raltegravir. Raltegravir-linked AuNPs shows inhibition of HIV replication. AuNPs conjugated siRNA is more stable than free siRNA so that it has greater activity in inhibiting dengue virus replication [17].

AgNPs are metallic nanoparticles that are widely used as antivirals. Synthesis of AgNPs, as well as metallic nanoparticles, is carried out physically, chemically, and biologically. Biologically synthesis of AgNPs has become popular because it is cost-effective, simple and has a high yield. This biological synthesis is also friendly to the environment because it does not use hazardous or toxic materials. The advantage of this biological method is the use of biological sources as reducing agents, which makes the resulting AgNPs have high stability, short production time, and are ready to dissolve [95].
AgNPs is metallic nanoparticles that is most effective against bacteria, viruses, and other eukaryotic microorganisms, due to the silver's inhibition and bactericidal properties. In addition, it is also due to the fact that Ag has good conductivity, catalytic properties, and chemical stability. The mechanism of AgNPs as an antimicrobial is by releasing silver ions (increasing antimicrobial activity), damaging cell membranes and damaging DNA [91]. As an antiviral agent, AgNPs have 2 mechanisms, namely 1 ) it interacts with the surface of the virus and prevents the virus from sticking to the receptors; 2) AgNPs will bind to viral DNA or RNA, thereby inhibiting viral replication or propagation in the host cell [95].

Tannic acid-modified AgNPs have been shown to have antiviral activity against Herpes simplex virus type 2 (HSV-2). Tannic acidmodified AgNPs interact with viral glycoproteins and thus interfere with adherence to host cells [96]. The mechanism of action of chitosan-coated AgNPs as antiviral H1N1 influenza A is to prevent virus contact with host cells and interaction between AgNPs and viral glycoproteins. It is known that in this system, the size of the AgNPs determines the antiviral activity. The antiviral activity is getting stronger as the size of the AgNPs in the composite gets smaller [97]. AgNPs also have activity against Hepatitis B Virus (HBV) by reducing HBV DNA formation through the bond between HBV DNA and virions [96]. Sarkar in his opinion letter [98] stated that AgNPs have activity as antiviral SARS-CoV-2 with low side effects. The hypothesis of AgNPs as antiviral SARS-CoV-2 is through the binding of the virus S-glycoprotein with AgNPs so that it will inhibit the binding of the virus with ACE2 host cells; thus the virus cannot enter the host cell. Another possible mechanism is the release of $\mathrm{Ag}$ ions. The release of $\mathrm{Ag}$ ions will cause the environmental $\mathrm{pH}$ of the respiratory epithelium to decrease, the $\mathrm{pH}$ becomes more acidic and is not suitable for viruses [98].

\section{CONCLUSION}

Nanoparticles are a drug delivery system that is suitable for use in antiviral drugs, including to treat SARS-CoV-2. Why is it appropriate? Because nanoparticles are able to improve the delivery of waterinsoluble antiviral drugs, increasing efficiency and minimizing side effects of antiviral drugs. The development of SARS-CoV-2 antiviral can be developed to target spike protein, ACE-2, TMRSS-2, 3CLpro, PLpro, and RdRp so that the drug becomes more effective and at the same time minimize drug toxicity. Nanoparticles can accommodate the need to develop these targeted drugs so that effective antiviral drugs can be produced and minimize side effects.

\section{ACKNOWLEDGEMENT}

The authors would like to express gratitude to Safri Sekti Wibowo for helping me to draw the picture in this article.

\section{FUNDING}

Nil

\section{AUTHOR CONTRIBUTION}

All the work have been carried out by me.

\section{CONFLICT OF INTERESTS}

\section{Declared none}

\section{REFERENCES}

1. Tarighi P, Eftekhari S, Chizari M, Sabernavaei M, Jafari D, Mirzabeigi P. A review of potential suggested drugs for coronavirus disease (COVID-19) treatment. Eur J Pharmacol 2021;895:173890.

2. Mukherjee S, Mazumder P, Joshi M, Joshi C, Dalvi SV, Kumar M. Biomedical application, drug delivery and metabolic pathway of antiviral nanotherapeutics for combating viral pandemic: a review. Environ Res 2020;191:110-9.

3. Carter DC, Wright B, Jerome WG, Rose JP, Wilson E. A unique protein self-assembling nanoparticle with significant advantages in vaccine development and production. J Nanomater 2020. https://doi.org/10.1155/2020/4297937

4. Huang F, Li Y, Leung ELH, Liu X, Liu K, Wang Q, et al. A review of therapeutic agents and Chinese herbal medicines against SARS-COV-2 (COVID-19). Pharmacol Res 2020;158:104929. 
5. Walls AC, Park YJ, Tortorici MA, Wall A, McGuire AT, Veesler D. Structure, function, and antigenicity of the SARS-CoV-2 spike glycoprotein. Cell 2020;180:281-92.

6. Mehta M, Prasher P, Sharma M, Shastri MD, Khurana N, Vyas M, et al. Advanced drug delivery systems can assist in targeting coronavirus disease (COVID-19): a hypothesis. Med Hypotheses 2020;144:110254.

7. Lam S, Lombardi A, Ouanounou A. COVID-19: a review of the proposed pharmacological treatments. Eur J Pharmacol 2020;886:1-5.

8. Alavi M, Asare Addo $\mathrm{K}$, Nokhodchi A. Lectin protein as a promising component to functionalize micelles, liposomes and lipid nps against coronavirus. Biomedicines 2020;8:1-16.

9. Zumla A, Chan JFW, Azhar EI, Hui DSC, Yuen KY. Coronavirusesdrug discovery and therapeutic options. Nat Rev Drug Discovery 2016;15:327-47.

10. Chan Y, Ng SW, Mehta M, Anand K, Kumar Singh S, Gupta G, et al. Advanced drug delivery systems can assist in managing influenza virus infection: a hypothesis. Med Hypotheses 2020;144:110298.

11. Cojocaru FD, Botezat D, Gardikiotis I, Uritu CM, Dodi G, Trandafir L, et al. Nanomaterials designed for antiviral drug delivery transport across biological barriers. Pharmaceutics 2020;12:1-34.

12. Canta F, Marrone R, Bonora S, D'Avolio A, Sciandra M, Sinicco A et al. Pharmacokinetics and hepatotoxicity of lopinavir/ritonavir in non-cirrhotic HIV and hepatitis C virus (HCV) co-infected patients. J Antimicrob Chemother 2005;55:280-1.

13. Liu J, Cao $\mathrm{R}, \mathrm{Xu} \mathrm{M}$, Wang $\mathrm{X}$, Zhang $\mathrm{H}, \mathrm{Hu} \mathrm{H}$, et al. Hydroxychloroquine, a less toxic derivative of chloroquine, is effective in inhibiting SARS-CoV-2 infection in vitro. Cell Discovery 2020;6:6-9.

14. Sahakijpijarn S, Moon C, Koleng JJ, Williams RO. Development of remdesivir as a dry powder for inhalation by thin film freezing. bioRxiv 2020;12:1-28.

15. Singh M, Kaur R, Rajput R, Agarwal S, Kumar S, Sharma M, et al. Analysis of process and formulation variables on chitosan based losartan potassium nanoparticles: preparation, validation and in vitro release kinetics. Recent Innov Chem Eng (Formerly Recent Patents Chem Eng) 2019;13:41-54.

16. Sharun K, Shyamkumar TS, Aneesha VA, Dhama K, Pawde AM, Pal A. Current therapeutic applications and pharmacokinetic modulations of ivermectin. Vet World 2019;12:1204-11.

17. Augustine R, Ashkenazi DL, Arzi RS, Zlobin V, Shofti R, Sosnik A. Nanoparticle-in-microparticle oral drug delivery system of a clinically relevant darunavir/ritonavir antiretroviral combination. Acta Biomater 2018;74:344-59.

18. Maus A, Strait L, Zhu D. Nanoparticles as delivery vehicles for antiviral therapeutic drugs. Eng Regen 2021;2:31-46.

19. Joseph SK, MAA, Thomas S, Nair SC. State-of-the-art nanotechnology-based drug delivery strategies to combat covid-19. Int J Appl Pharm 2021;13:18-29.

20. Li T, Zhang T, Gu Y, Li S, Xia N. Current progress and challenges in the design and development of a successful COVID-19 vaccine. Fundam Res 2021;1:139-50.

21. Hempel T, Raich L, Olsson S, Azouz NP, Klingler AM, Hoffmann $\mathrm{M}$, et al. Molecular mechanism of inhibiting the SARS-CoV-2 cell entry facilitator TMPRSS2 with camostat and nafamostat. Chem Sci 2021;12:983-92.

22. Ragia G, Manolopoulos VG. Inhibition of SARS-CoV-2 entry through the ACE2/TMPRSS2 pathway: a promising approach for uncovering early COVID-19 drug therapies. Eur J Clin Pharmacol 2020;76:1623-30.

23. Hoffmann M, Hofmann Winkler H, Smith JC, Kruger N, Arora P, Sorensen LK, et al. Camostat mesylate inhibits SARS-CoV-2 activation by TMPRSS2-related proteases and its metabolite GBPA exerts antiviral activity. EBioMedicine 2021;65. DOI:10.1101/2020.08.05.237651

24. Yao $\mathrm{X}$, Ye $\mathrm{F}$, Zhang $\mathrm{M}$, Cui $\mathrm{C}$, Huang $\mathrm{B}$, Niu $\mathrm{P}$, et al. In vitro antiviral activity and projection of optimized dosing design of hydroxychloroquine for the treatment of severe acute respiratory syndrome coronavirus 2 (SARS-CoV-2). Clin Infect Dis 2020;71:732-9.

25. Uzunova K, Filipova E, Pavlova V, Vekov T. Insights into antiviral mechanisms of remdesivir, lopinavir/ritonavir and chloroquine/hydroxychloroquine affecting the new SARS-CoV2. Biomed Pharmacother 2020;131:110668.

26. Zhang J, Ma X, Yu F, Liu J, Zou F, Pan T, et al. Teocoplanin potently blocks the cell entry of 2019-nCoV. BioRxiv 2020.

27. Du YX, Chen XP. Favipiravir: pharmacokinetics and concerns about clinical trials for 2019-nCoV infection. Clin Pharmacol Ther 2020;108:242-7.

28. Khanal P. Remdesivir for COVID-19 treatment: mechanism of action, synthesis, and clinical trials. World J Pharm Pharm Sci 2020;9:1062-8.

29. Khalili JS, Zhu H, Mak NSA, Yan Y, Zhu Y. Novel coronavirus treatment with ribavirin: Groundwork for an evaluation concerning COVID-19. J Med Virol 2020;92:740-6.

30. Caly L, Druce JD, Catton MG, Jans DA, Wagstaff KM. The FDAapproved drug ivermectin inhibits the replication of SARS-CoV2 in vitro. Antiviral Res 2020;178:3-6.

31. Palmer J, Dobrovolny HM, Beauchemin CAA. The in vivo efficacy of neuraminidase inhibitors cannot be determined from the decay rates of influenza viral titers observed in the treated patients. Sci Rep 2017;7:1-12.

32. Pant S, Singh M, Ravichandiran V, Murty USN, Srivastava HK. Peptide-like and small-molecule inhibitors against covid-19. J Biomol Struct Dyn 2020;39:1-10.

33. Mahmoud DB, Shitu Z, Mostafa A. Drug repurposing of nitazoxanide: can it be an effective therapy for COVID-19? J Genet Eng Biotechnol 2020;18:35.

34. Lokhande AS, Devarajan PV. A review on possible mechanistic insights of nitazoxanide for repurposing in COVID-19. Eur J Pharmacol 2021;891:173748.

35. Kiplin Guy R, DiPaola RS, Romanelli F, Dutch RE. Rapid repurposing of drugs for COVID-19. Science 2020;368:829-30.

36. Zhou Y, Wang F, Tang J, Nussinov R, Cheng F. Artificial intelligence in COVID-19 drug repurposing. Lancet Digit Heal 2020;2:667-76.

37. Parvathaneni V, Gupta V. Utilizing drug repurposing against COVID-19-Efficacy, limitations, and challenges. Life Sci 2020;259:118275.

38. Cai Q, Yang M, Liu D, Chen J, Shu D, Xia J, et al. Experimental treatment with favipiravir for COVID-19:An open-label control study. Engineering 2020;6:1192-8.

39. Li Y, Xie Z, Lin W, Cai W, Wen C, Guan Y, et al. An exploratory randomized controlled study on the efficacy and safety of lopinavir/ritonavir or arbidol treating adult patients hospitalized with mild/moderate COVID-19 (ELACOI). medRxiv 2020;1-33. https://doi.org/10.1101/2020.03.19.20038984

40. Buzea C, Pacheco II, Robbie K. Nanomaterials and nanoparticles: sources and toxicity. Biointerphases 2007;2:17-71.

41. Reverchon E, Adami R. Nanomaterials and supercritical fluids. J Supercrit Fluids 2006;37:1-22.

42. Jahangirian H, Lemraski EG, Webster TJ, Rafiee Moghaddam R, Abdollahi Y. A review of drug delivery systems based on nanotechnology and green chemistry: green nanomedicine. Int J Nanomed 2017;12:2957-78.

43. Din Fud W, Aman A, Ullah I, Qureshi OS, Mustapha O. Effective use of nanocarriers as drug delivery systems for the treatment of selected tumors. Int J Nanomed 2017;12:7291-309.

44. Chowdhury A, Kunjiappan S, Panneerselvam T, Somasundaram B, Bhattacharjee C. Nanotechnology and nano carrier-based approaches on the treatment of degenerative diseases. Int Nano Lett 2017;7:91-122.

45. Banerjee R. Nanotechnology in drug delivery: present status and a glimpse into the future. Ther Delivery 2018;9:231-2.

46. Abed SN, Deb PK, Surchi HS, Kokaz SF, Jamal SM, Bandopadhyay S, et al. Nanocarriers in different preclinical and clinical stages. In: Basic fundamentals of drug delivery. Elsevier Inc; 2018. p. 685-731.

47. Rizvi SAA, Saleh AM. Applications of nanoparticle systems in drug delivery technology. Saudi Pharm J 2018;26:64-70.

48. Daraee H, Etemadi A, Kouhi M, Alimirzalu S, Akbarzadeh A. Application of liposomes in medicine and drug delivery. Artif Cells Nanomed Biotechnol 2016;44:381-91.

49. Akbarzadeh A, Rezaei Sadabady R, Davaran S, Joo SW, Zarghami $\mathrm{N}$, Hanifehpour $\mathrm{Y}$, et al. Liposome: classification, preparation, and applications. Nanoscale Res Lett 2013;8:1. 
50. Milovanovic M, Arsenijevic A, Milovanovic J, Kanjevac T, Arsenijevic N. Nanoparticles in antiviral therapy. Antimicrob Nanoarchitectonics 2017;383-410. https://doi.org/10.1016/B978-0-323-52733-0.00014-8

51. Croci R, Bottaro E, Chan KWK, Watanabe S, Pezzullo M, Mastrangelo E, et al. Liposomal systems as nanocarriers for the antiviral agent ivermectin. Int J Biomater 2016. DOI:10.1155/2016/8043983

52. Yang KC, Lin JC, Tsai HH, Hsu CY, Shih V, Hu CMJ. Nanotechnology advances in pathogen-and host-targeted antiviral delivery: multipronged therapeutic intervention for pandemic control. Drug Delivery Transl Res 2021;11:1420-37.

53. Serrano G, Kochergina I, Albors A, Diaz E, Oroval M, Hueso G, et al. Liposomal lactoferrin as potential preventative and cure for COVID-19. Int J Res Heal Sci 2020;8:8-15.

54. Tai TT, Wu TJ, Wu HD, Tsai YC, Wang HT, Wang AM, et al. A strategy to treat COVID-19 disease with targeted delivery of inhalable liposomal hydroxychloroquine: a preclinical pharmacokinetic study. Clin Transl Sci 2021;14:132-6.

55. Torchilin VP. Micellar nanocarriers: pharmaceutical perspectives. Pharm Res 2007;24:1-16.

56. Lembo D, Cavalli R. Nanoparticulate delivery systems for antiviral drugs. Antivir Chem Chemother 2010;21:53-70.

57. Sawdon AJ, Peng CA. Polymeric micelles for acyclovir drug delivery. Colloids Surf B 2014;122:738-45.

58. Baker VS. Acyclovir for SARS-CoV-2: a clinical practice old drug with a new purpose. Clin Pract 2021;18:1584-92.

59. Craparo EF, Triolo D, Pitarresi G, Giammona G, Cavallaro G. Galactosylated micelles for a ribavirin prodrug targeting to hepatocytes. Biomacromolecules 2013;14:1838-49.

60. Liang L, Ahamed A, Ge L, Fu X, Lisak G. Advances in antiviral material development. Chempluschem 2020;85:2105-28.

61. Govender T, Ojewole E, Naidoo P, Mackraj I. Polymeric nanoparticles for enhancing antiretroviral drug therapy. Drug Delivery 2008;15:493-501.

62. Chakravarty M, Vora A. Nanotechnology-based antiviral therapeutics. Drug Delivery Transl Res 2020;3:1-40.

63. Torchilin VP. Multifunctional nanocarriers. Adv Drug Delivery Rev 2012;64 Suppl 1:302-15.

64. Abo Zeid Y, Garnett MC. Polymer nanoparticle as a delivery system for ribavirin: Do nanoparticle avoid uptake by red blood cells? J Drug Delivery Sci Technol 2020;56:101552.

65. Wu LS, Rower JE, Burton JR, Anderson PL, Hammond KP, Baouchi Mokrane F, et al. Population pharmacokinetic modeling of plasma and intracellular ribavirin concentrations in patients with chronic hepatitis C virus infection. Antimicrob Agents Chemother 2015;59:2179-88.

66. Duan Y, Dhar A, Patel C, Khimani M, Neogi S, Sharma P, et al. A brief review on solid lipid nanoparticles: Part and parcel of contemporary drug delivery systems. RSC Adv 2020;10:26777-91.

67. Thi TTH, Suys EJA, Lee JS, Nguyen DH, Park KD, Truong NP. Lipid-based nanoparticles in the clinic and clinical trials: from cancer nanomedicine to COVID-19 vaccines. Vaccines 2021;9:359.

68. Basha SK, Dhandayuthabani R, Muzammil MS, Kumari VS. Solid lipid nanoparticles for oral drug delivery. In: Materials Today: Proceedings. Elsevier Ltd; 2020. p. 313-24.

69. Kiran S, Pindiprolu SS, Phani CS, Sampath V, Golla K. Pulmonary delivery of nanostructured lipid carriers for effective repurposing of salinomycin as an antiviral agent. Med Hypotheses 2020;143:19-22.

70. Ravi PR, Vats R, Dalal V, Murthy AN. A hybrid design to optimize the preparation of lopinavir-loaded solid lipid nanoparticles and comparative pharmacokinetic evaluation with marketed lopinavir/ritonavir coformulation. J Pharm Pharmacol 2014;66:912-26.

71. Javan F, Vatanara A, Azadmanesh K, Nabi Meibodi M, Shakouri M. Encapsulation of ritonavir in solid lipid nanoparticles: in vitro anti-HIV-1 activity using lentiviral particles. J Pharm Pharmacol 2017;69:1002-9.

72. Fang CL, A Al-Suwayeh S, Fang JY. Nanostructured lipid carriers (NLCs) for drug delivery and targeting. Recent Pat Nanotechnol 2013;7:41-55.
73. Chauhan I, Yasir M, Verma M, Singh AP. Nanostructured lipid carriers: a groundbreaking approach for transdermal drug delivery. Adv Pharm Bull 2020;10:150-65.

74. Garcia Pinel B, Porras Alcala C, Ortega Rodriguez A, Sarabia F, Prados J, Melguizo C, et al. Lipid-based nanoparticles: application and recent advances in cancer treatment. Nanomaterials 2019;9:1-23.

75. Salvi VR, Pawar P. Nanostructured lipid carriers (NLC) system: a novel drug targeting carrier. J Drug Delivery Sci Technol 2019;51:255-67.

76. Haider M, Abdin SM, Kamal L, Orive G. Nanostructured lipid carriers for delivery of chemotherapeutics: a review. Pharmaceutics 2020;12:228.

77. Khan AA, Mudassir J, Akhtar S, Murugaiyah V, Darwis Y. Freezedried lopinavir-loaded nanostructured lipid carriers for enhanced cellular uptake and bioavailability: statistical optimization, in vitro and in vivo evaluations. Pharmaceutics 2019;11:1-19.

78. Garg B, Beg S, Kumar R, Katare OP, Singh B. Nanostructured lipidic carriers of lopinavir for effective management of HIVassociated neurocognitive disorder. J Drug Delivery Sci Technol 2019;53:101220.

79. Franiak Pietryga I, Ziemba B, Messmer B, Skowronska Krawczyk. Dendrimer as drug nanocarriers: the future of gene therapy and targeted therapies in cancer. In: Dendrimer: Fundamental and Applications; 2013. p. 137-44.

80. Caminade AM, Turrin CO. Dendrimers for drug delivery. J Mater Chem B 2014;23:1-12.

81. Chauhan AS. Dendrimers for drug delivery. Molecules 2018;23:938.

82. Nimesh S. Gene therapy. $1^{\text {st }}$ ed. Cambridge, UK: Woodhead Publishing; 2013.

83. Sandoval Yanez C, Rodriguez CC. Dendrimers: amazing platforms for bioactive molecule delivery systems. Materials (Basel) 2020;13:1-20.

84. Choudhary S, Gupta L, Rani S, Dave K, Gupta U. Impact of dendrimers on the solubility of hydrophobic drug molecules. Front Pharmacol 2017;8:1-23.

85. Falanga A, Del Genio V, Galdiero S. Peptides and dendrimers: how to combat viral and bacterial infections. Pharmaceutics 2021;13:1-23.

86. Kandeel M, Al-Taher A, Park BK, Kwon HJ, Al-Nazawi M. A pilot study of the antiviral activity of anionic and cationic polyamidoamine dendrimers against the Middle East respiratory syndrome coronavirus. J Med Virol 2020;92:166570.

87. Filipezak N, Yalamarty SSK, Li X, Parveen F, Torchilin V. Developments in treatment methodologies using dendrimers for Infectious diseases. Molecules 2021;26:1-32.

88. Li W, Cao Z, Liu R, Liu L, Li H, Li X, et al. AuNPs as an important inorganic nanoparticle applied in drug carrier systems. Artif Cells Nanomed Biotechnol 2019;47:4222-33.

89. Ahmad MZ, Akhter S, Jain GK, Rahman M, Pathan SA, Ahmad FJ, et al. Metallic nanoparticles: technology overview and drug delivery applications in oncology. Expert Opin Drug Delivery 2010;7:927-42.

90. Singh L, Kruger HG, Maguire GEM, Govender T, Parboosing R. The role of nanotechnology in the treatment of viral infections. Ther Adv Infect Dis 2017;4:105-31.

91. Maduray K, Parboosing R. Metal nanoparticles: a promising treatment for viral and arboviral infections. Biol Trace Elem Res 2020;7:1-18.

92. Ajnai G, Chiu A, Kan T, Cheng CC, Tsai TH, Chang J. Trends of gold nanoparticle-based drug delivery system in cancer therapy. J Exp Clin Med 2014;6:172-8.

93. Khan AK, Rashid R, Murtaza G, Zahra A. Gold nanoparticles: synthesis and applications in drug delivery. Trop J Pharm Res 2014;13:1169-77.

94. Kong FY, Zhang JW, Li RF, Wang ZX, Wang WJ, Wang W. Unique roles of gold nanoparticles in drug delivery, targeting and imaging applications. Molecules 2017;22:1445.

95. Salleh A, Naomi R, Utami ND, Mohammad AW, Mahmoudi E, Mustafa $\mathrm{N}$, et al. The potential of silver nanoparticles for 
antiviral and antibacterial applications: a mechanism of action. Nanomaterials 2020;10:1-20.

96. Orlowski P, Tomaszewska E, Gniadek M, Baska P, Nowakowska J, Sokolowska J, et al. Tannic acid-modified silver nanoparticles show antiviral activity in herpes simplex virus type 2 infection. PLoS One 2014;9:1-15.
97. Mori Y, Ono T, Miyahira Y, Nguyen VQ, Matsui T, Ishihara M. Antiviral activity of silver nanoparticle/chitosan composites against H1N1 influenza a virus. Nanoscale Res Lett 2013;8:93.

98. Sarkar S. Silver nanoparticles with bronchodilators through nebulisation to treat covid 19 patients. J Curr Med Res Opin 2020;3:449-50. 